\title{
About some incredible adventures of the "elusive" duty construction
}

\section{N. N. Tarusina ${ }^{1}$}

${ }^{1}$ P. G. Demidov Yaroslavl State University, 14 Sovetskaya str., Yaroslavl 150003, Russian Federation

DOI: 10.18255/1996-5648-2021-2-220-231

Research article

Full text in Russian

The article gives "biographies" of the construction of duty in atypical situations. The first of them is illustrated by the example of family legal relations between parents and children, in which parents are at the same time responsibilities for upbringing (the structure of right-duty). The doctrine accepts such a feature of the aforementioned type of legal relationship by no means to everyone - a reference to the classical interaction of the pair "right and duty" and their distribution between the subject. An additional argument is the arguments in favor of the child's incapacity and, consequently, the inadmissibility of imposing any responsibilities on him. As counterarguments, considerations are expressed about the possibility of the existence of exceptions from classical constructions, as well as about the presence of certain elements of legal capacity in the child, which make it possible to assign certain responsibilities to him, including in relation to parents or persons substituting for them. As additional argumentation, examples are given of assigning children of different ages (6, 10, 14 years) to responsibilities in the field of education, family, civil turnover. It is proposed to provide for the obligation of children to respect their parents in the general principles of family law. The second atypical situation arises when the so-called declarative obligations are fixed in the text of the law. It is emphasized that they, either directly or indirectly, are associated with certain legal consequences of their non-compliance, therefore, they possess, albeit not in the classical execution, the properties of a legal obligation.

Keywords: duty; right-duty; declarative norm; specifics of consolidation

\section{INFORMATION ABOUT AUTHORS}

Tarusina, Nadezhda N. | E-mail: nant@uniyar.ac.ru

ORCID 0000-0001-8827-5532

Cand. Sc. (Jurisprudence), Professor

Funding: Yaroslavl State University, project VIP-014. 


\title{
О некоторых невероятных приключениях «неуловимой» конструкции обязанности
}

\author{
Н. Н. Тарусина ${ }^{1}$
}

${ }_{1}^{1}$ Ярославский государственный университет им. П. Г. Демидова, ул. Советская, 14, Ярославль, 150003, Российская Федерация

DOI: $10.18255 / 1996-5648-2021-2-220-231$

УдК 340.132 .1

Научная статья

В статье даются «жизнеописания» конструкции обязанности в нетипичных юридических ситуациях. Первая из них иллюстрируется на примере семейных правоотношений между родителями и детьми, в которых права родителей по воспитанию одновременно являются и обязанностями (конструкция право-обязанности). В доктрине принимается такая особенность означенного вида правоотношений далеко не всеми - со ссылкой на классическое взаимодействие пары «право и обязанность» и их распределенность между субъектами. Дополнительным аргументом служит соображение о недееспособности ребенка и, следовательно, недопустимости возложения на него каких бы то ни было обязанностей. В качестве контраргументов высказываются соображения о возможности существования исключений из классических конструкций, а также о наличии у ребенка отдельных элементов дееспособности, позволяющих возложить на него определенные обязанности, в том числе и по отношению к родителям или лицам, их замещающим. В качестве дополнительной аргументации приводятся примеры закрепления за детьми разного возраста $(6,10,14$ лет) обязанностей в сфере образования, семьи, гражданского оборота. Предлагается предусмотреть обязанность детей уважать своих родителей в общих началах семейного законодательства. Вторая нетипичная ситуация возникает, когда в тексте закона фиксируются так называемые обязанности декларативного типа. Подчеркивается, что и они - либо прямо, либо опосредованно -связаны с определенными правовыми последствиями своего несоблюдения, следовательно, обладают, пусть и не в классическом исполнении, свойствами юридической обязанности.

Ключевые слова: обязанность; право-обязанность; декларативная норма; специфика закрепления

\section{ИНФОРМАЦИЯ ОБ АВТОРАХ}

Тарусина, Надежда Николаевна

E-mail: nant@uniyar.ac.ru

ORCID 0000-0001-8827-5532

Кандидат юридических наук, профессор,

Заслуженный юрист РФ

Финансирование: ЯрГУ, проект VIP-014.

(C) Тарусина Н. Н., 2021

Статья открытого доступа под лицензией CC BY (https://creativecommons.org/licenses/by/4.0/) 
Тарусина Н. Н.

Несмотря на интригующе-агрессивный контекст заголовка статьи, речь пойдет о вполне мирных элементарных частицах юридического пространства - о конструкции права-обязанности и о конструкции так называемых декларативных обязанностей. Демонстрация первой будет осуществлена на примере из области гражданского процесса и сферы семейного права, а второй - в рамках медицинского и семейного законодательства.

На фракт «сдвоенности» права-обязанности в семейно-правовой сфере обращал внимание еще Г. Ф. Шершеневич: «Для родителей составляет право и вместе обязанность воспитание детей» [1, с. 625]. Другого классика цивилистики, О. С. Иоффе, также не смущала эта странность, явная нетипичность положения. В то же время он пытался ее встроить в обычные рамки: противоречие канонам, полагал автор, лишь кажущееся, ибо очевидно, что правам родителей соответствуют обязанности, а родительским обязанностям - правомочия детей, то есть наличествует классическая корреспонденция прав и обязанностей [2, с. 238-239]. Однако данную классику некоторым образом разрушает то обстоятельство, что в семейном законе об обязанностях детей речи вовсе нет. Впрочем, на данном этапе размышлений нам придется эту констатацию отодвинуть в сторону, ибо рассуждение о вопросе наличия/отсутствия у детей семейно-правовых обязанностей запланирован нами во второй части сочинения.

В доктрине высказываются соображения и совершенно иного порядка. Так, А. М. Нечаева разрешает означенную дихотомию в каком-то смысле с помощью филологии: воспитание является родительским правом, а надлежащее воспитание - обязанностью [3, с. 105-106]. Пытаясь найти «свет в конце тоннеля», автор в более поздней работе подчеркивает, что данное право родителей сближает с их же обязанностью наличие в первой компоненте меры дозволения, так как право отнюдь не безгранично [4, с. 18]. Однако, полагаем, хотя этот аргумент верен, в том числе в силу своей очевидности, это его качество лишь характеризует субъективное право, которое всегда имеет своим собственным антиподом (или возможным вариантом своего развития в процессе реализации) злоупотребление правом [5, с. 46-47]. И не характеризует это право в спайке с обязанностью: да, обладатель субъективного права - в нашем случае права на воспитание ребенка - не должен выходить за законные пределы его возможностей, кои, как правило, очерчены с помощью конструкции «интересы ребенка», пусть не вполне определенной, но вполне способной дать пищу для собственного толкования - на уровне общего размышления о ее содержании и применительно к частному (конкретному) случаю. Благо, неизбежность правоприменительного (административного, судебного) усмотрения никто не оспаривает, особенно в сфере семейного права, средоточии норм с относительно определенным (относительно неопределенным) содержа- 
нием [6, с. 73-76; 7, с. 50-53]. Но злоупотребления правом отнюдь не свидетельствуют о его «переходе в состояние обязанности».

В. Н. Леженин, опираясь на фрормулу теории права «либо право, либо обязанность», утверждает: право на воспитание есть результат свободного, добровольного возложения на себя соответствующих правомочий (статика), а обязанность возникает при осуществлении права (динамика) [8, с. 58-59]. По сути, автор повторяет сентенцию В. П. Грибанова [5] только в привязке к своей задаче объяснить невозможность сдвоенности конструкции.

Однако ни упование на уточняющий термин «надлежащее» (воспитание), ни разобщение на пассивную стадию (наличие права) и активную стадию (осуществление права воспитания - обязанность) не позволяют получить ясную картину этой части родительско-детского мира. Означенная статика скорее «вовлекает» нас в пространство правоспособности (как одной из предпосылок правоотношения) и правового статуса (как совокупности прав и обязанностей). Динамика же есть неотъемлемое качество субъективного права в его рабочем состоянии (для чего оно, собственно, и предназначено): свобода распоряжения, возможность как оставить субъективное право в состоянии покоя (неосуществления), так и привести его в «боевое состояние» осуществления составляет классику теории права $[9$, с. 127$]$.

А. М. Рабец, не отрицая традиции признания феноменом семейно-правовой сореры означенную нами «спайку», тем не менее, вслед за В. Н. Лежениным, полагает его противоречащим аксиоме теории права о парности конструкции права и обязанности как самостоятельных характеристик правового статуса родителей, а также представляющим практическую опасность: неспособные к воспитанию родители могут без вины подвергнуться жестким мерам семейно-правового воздействия (ст. 69, 73 СК РФ), поэтому следует сместить акценты в пользу права [10]. Весьма странная логика: если граждане не способны выполнять обязанности, следует «передвинуть стрелки» в пользу права... Однако подобная неспособность как раз и является основанием применения мер защиты интересов ребенка -оперативных мер воздействия к родителям, а при отсутствии вины мер, адекватных обстоятельствам (например, временное отобрание ребенка). При этом «смещение акцентов» не приведет к разрешению проблемы: «двойняшки» останутся.

Н. Д. Егоров, полагая ситуацию с означенными «двойняшками» недоразумением, распределяет данные состояния по двум различным правоотношениям - абсолютным и относительным: право родителей на воспитание детей существует в рамках абсолютного, что предполагает воздержание неопределенного круга лиц от действий препятствующего 
Тарусина Н. Н.

характера, а их обязанность - в рамках относительного правоотношения, которой корреспондируют права детей. При этом классическая дихотомия «права-обязанности» автором исключается как нелепость, ибо малолетние дети к обязанию призываться не могут [11, с. 296]. Однако его соавторы не разделяют данной позиции, допуская, как и О. С. Иофрфе, обсуждаемое единство в качестве исключения из общего правила для столь специфических правоотношений, в которых непосредственным участником является ребенок: праву родителей соответствует обязанность детей не чинить им препятствия в его осуществлении, а обязанности родителей - право детей требовать надлежащего воспитания [11, с. 307]. Усиливая данную позицию, Н. И. Матузов отмечает, что в ряде случаев подобное слияние является следствием объективного характера взаимосвязей, а не недостатком законодательства и правовой системы $[12, \text { с. } 59]^{1}$. Полагаем, что на этом пока можно поставить «запятую», продолжив размышление во второй части сочинения, которая и посвящена проблеме нетипичных обязанностей. Дополним лишь уже предложенные рассуждения вполне очевидным соображением о том, что “двойной эфрфект» характерен также и для ряда других семейных правоотношений, сущностно близких родительско-детским, - правоотношениям попечительства и усыновления/удочерения. Так что “...ходит песенка по кругу»: право-обязанность-обязанность-право. За пределами данного круга остаются отношения по фактическому воспитанию, ибо в них, пока законодатель не примет иного решения, не возникает ни субъективных прав, ни юридических обязанностей, а лишь этико-бытийные их аналоги.

В теории гражданского процесса дискутируемая конструкция также себя обнаруживает. Так, например, считается, что применение судебного усмотрения при разрешении гражданского дела (если в его юридической основе лежат ситуационные или т. п. нормы) является и правом, и обязанностью суда [14, с. 23]. При этом следует заметить, что некоторые гражданско-процессуальные нормы обладают лишь видимостью диспозитивности и дихотомическим единством, а в действительности относятся к императивным, то есть к обязанностям, - проблема в некорректных фрормулировках. Например, правило п. 1 ст. 43 ГПК РФ сообщает суду и участникам процесса о возможности привлечения в процесс третьих лиц. Очевидно, что возможность есть характеристика правомочия. Однако, по сути, суд обязан осуществить данное действие, ибо манкирование им подвергнет сомнению преюдициальность судебного решения. Аналогичные комментарии можно дать и относительно большинства других “усмотренческих»

${ }^{1}$ Более подробный анализ см. в других наших трудах [13]. Следует заметить, что в некоторых зарубежных законодательствах такой «сдвоенности» нет. Так, например, в ч. 1 ст. 68 Семейного кодекса Болгарии закреплены именно обязанности родителей заботиться о детях и готовить их к общественно полезному труду. 
полномочий суда: характер нормы с относительно определенным содержанием не предлагает, а требует конкретизации, применения аналогии или субсидиарного использования других норм. И т. д. Следовательно, необходимо, наряду с признанием некоторого числа исключений (конструкции права-обязанности) $)^{2}$, подвергнуть нормы неопределенного типа (в слабость их фрормулировки ${ }^{3}$ простой фрллологической операции - приведением терминологии в соответствие с императивным смыслом.

Во второй части сочинения поразмышляем о декларативных обязанностях или "необязанностях». Данные несколько мифические конструкции также характеризуют родительско-детские отношения. С одной стороны, наличие у родителей прав в отношении своих детей должно предполагать обязанности последних. С другой стороны, не только Семейный кодекс РФ не упоминает о таковых обязанностях, но и большинство доктринальных толкователей его содержания не допускают их юридического существования, объявляя противоположное "нелепостью», «недоразумением» или «опасным дисбалансом» (см. предыдущие рассуждения). Однако, как мы уже отметили ранее, ряд цивилистов не видят никакого «юридического ужаса» в допущении у детей юридических обязанностей. Так, О. С. Иофрфе, продолжая свои размышления о специфике семейно-правового статуса родителей, подчеркивает: «Упоминание в кодексе о правах родителей по отношению к детям уже само по себе должно было бы свидетельствовать о возложении на детей обязанностей, соответствующих этим правам». Поскольку, продолжает автор, родителям, как бы по умолчанию, разрешается «применять к детям любые непротивоправные и не противоречащие принципам морали методы» и коль скоро они тем самым получают защиту закона, «налицо правовая охрана возлагаемых на детей обязанностей» [2, с. 238-239].

О. С. Иоффре формулировал свою позицию на основе прежнего законодательства (даже не КоБС РСФС 1969 г.). Нововведения СК РФ 1995 г. ее, безусловно, для автора усилили бы, так как в действующем законе не только имеется специальная глава о правах детей, но и фриксированы такие их возможности, как право на административную и судебную защиту (причем с 14 лет самостоятельно осуществляемую), право на мнение в форме дачи согласия на совершение ряда семейно-правовых актов (ст. 57 СК РФ), которое, кстати, по своей сущности и последствиям весьма напоминает ситуацию с обсужденными ранее «двойняшками», поскольку означенная конструкция согласия предполагает два варианта - позитив-

${ }^{2}$ Кстати, подобные конструкции-«двойняшки» вполне укладываются в концепцию M. А. Гурвича о гражданском процессе как сложном (комплексном) правоотношении.

${ }^{3}$ Употребление «в силу» здесь неуместно, хотя обыкновения русского языка именно таковы. 
Тарусина Н. Н.

ный и негативный и не предполагает «ухода в песок», то есть игнорирование правила.

Конечно, «нелепость» (в фрилологии оппонентов) принадлежности ребенка, ввиду его недееспособности, к обязанным субъектам права имеет существенно различную степень своего напряжения - в зависимости от возраста. При этом данные возрастные границы либо явным образом фиксированы (6 лет, 10 лет, 15 лет, 16 лет), либо размыты. Однако в определенном смысле можно утверждать, что обязанность, по крайней мере претерпевать заботу и воспитательное воздействие родителей, нижней возрастной планки не имеет: появился на свет - претерпевай.

Но данной констатацией содержание конструкции "детской обязанности» не исчерпывается. Так, мы неоднократно, с опорой на зарубежные образцы, предлагали закрепить в СК РФ обязанность детей уважительно относиться к своим родителям и участвовать, по мере сил и способностей, в делах семьи [14, с. 9-11]. Действительно, например, нормы Семейного кодекса Болгарии призывают детей уважать своих родителей, дедушку и бабушку и помогать им (ст. 69-70). Правило ст. 1619 Гражданского уложения Германии сообщает детям, что они должны посильным способом помогать родителям в домашнем хозяйстве и их делах. Норма ст. 87 польского Семейного и Опекунского кодекса предписывает родителям и детям уважать и поддерживать друг друга, ст. 95 предусматривает обязанность ребенка повиноваться родителям, а по вопросам, где он вправе принимать решения, - выслушивать мнения и рекомендации родителей, сорормулированные для его же блага. В параграфрах 854 и 885 Гражданского кодекса Чехии подтверждены обязанности родителей и детей взаимно уважать и поддерживать друг друга. Норма ст. 21 и 23 Закона КНP «О браке» также предписывает детям оказывать помощь родителям; дети также должны уважать право родителей на брак, не вмешиваться в вопрос о заключении повторного брака и в дальнейшую жизнь взрослых после его заключения. И т. д. ${ }^{4}$

После десятилетий законодательного замалчивания вопроса об обязанностях детей «первой ласточкой» наступающего сезона, свидетельствующей о некотором изменении подхода, явилась конституционная поправка, закрепленная в ч. 4 ст. 67.1 Конституции РФ, об уважении детей к старшим. Конечно, данное положение должно было дополнить содержание конституционной нормы ст. 38, как и заявление о понимании брака в качестве союза мужчины и женщины (поправка - к ч. 1 п. ж ст. 72). Однако это - уже совсем другой вопрос ${ }^{5}$ Гллавное, что первое из них является

${ }^{4}$ Несколько подробнее, а также и о других нормативных положениях см. труды других авторов [15].

${ }^{5}$ Процедурные аспекты внесения конституционных поправок критиковались и критикуются. См., например, статью С. П. Казанкова в данном номере Вестника. 
О некоторых невероятных приключениях «неуловимой» конструкции...

фундаментальной предпосылкой для внесения необходимых дополнений в общую часть СК РФ, то есть в начала семейного законодательства.

Соответствующая проектная поправка к ст. 1 СК РФ уже появилась. К сожалению, она избыточно общим образом описывает проблему должного взаимоотношения родителей и детей, ограничиваясь указанием на взаимную уважительность (и при этом - как бы между делом). Между тем не означенный в ней призыв к детям участвовать в делах семьи - вполне актуален и целесообразен, соответствует тем ценностным ориентирам, которым пытается следовать российский законодатель сегодняшнего дня. То, что подобные формулировки будут выглядеть как рецепция европейского законодательства, смущать не должно сразу по двум причинам. Первая: они принадлежат периоду далекому от постмодерна и отражают ценности, аналогичные российским. Вторая: даже и в настоящее время, несмотря на образцы экзотических решений в сфере семьи, мы не можем отказать европейскому праву в некоторой разумности по отдельным позициям ${ }^{6}$.

Возвращаясь к долженствующей составляющей дееспособности ребенка - в целом, а не только семейно-правовой, - вынуждены подчеркнуть, что семейное законодательство, а равным образом и цивилистическая доктрина находятся не только в противоречии с самими собой, но и в определенном несоответствии по данному вопросу с рядом других отраслей российского права (и их доктрин). Во-первых, положения ч. 2 ст. 28 ГК свидетельствуют о частичной дееспособности ребенка с 6 лет: если он вправе заключать мелкие бытовые сделки, то, значит, и нести обязанности по ней (например, произвести оплату товара). Во-вторых, нормативы ст. 43 ФЗ «Об образовании в Российской Федерации» не только предписывают обязанности школьников выполнять учебные задания, соблюдать учебную дисциплину, но и разрешают администрации школы привлекать их по завершении начального обучения, то есть примерно с 10 лет, к дисциплинарной ответственности. Какие-то странные у нас «разноотраслевые» дети.

Можно также поставить риторический вопрос: а дети в дошкольном учреждении не обязаны выполнять законные указания воспитательницы? И аналогичный: а дети, участвующие в киносъемках, не обязаны действовать по воле режиссера? (Контракт, заключенный их родителями, это предполагает). И т. д., и т. п. Достижение же несовершеннолетними 14 лет обогащает их статус и правом выбирать место жительства, и правом на заключение брака (при наличии регионального на то закона), и правом на самостоятельную судебную защиту по семейно-правовым вопросам,

О поправках см. также статью в первом номере Вестника за текущий год [16].

${ }^{6}$ Хотя в принципе готовы, совместно с К. Богомоловым, отцепить российский вагон от безумного поезда западного направления следования. 
Тарусина Н. Н.

и право-обязанностями в отношении своих детей, рожденных вне брака... Более того, 14 лет - минимальный возраст привлечения к уголовной ответственности за ряд тяжких преступлений. Или речь идет о праве быть привлеченным к оной ответственности???... Между тем даже для детей данного возраста в СК РФ нет указания на какое бы то ни было долженствование. Нонсенс и еще раз нонсенс. Все это свидетельствует о необходимости разумной корректировки семейного закона с учетом возрастных ступеней детства.

Одним из аргументов против закрепления общего положения об уважении детьми родителей (других воспитателей?) в началах семейного законодательства и главе $11 \mathrm{CK}$ РФ является отрицание за декларацией юридичности: нет конкретной ответственности за неисполнение обязанности - нет и самой обязанности. Да, по общему правилу это так. Однако что-то мы такое слышали про исключения из общего правила, которые его подтверждают... Кроме того, декларации-обязанности обычно все же подкреплены последствиями своего неисполнения, пусть и опосредованно, косвенным образом. Так, следствием декларации о взаимной поддержке членов семьи (ст. 1 СК РФ) может быть возникновение алиментного обязательства, или отступление от равенства долей при разделе общесупружеского имущества, или, наконец, следствием ненадлежащего поведения ребенка - помещение его в специнтернат. И т. д.

Кроме того, нравственные конструкты, в том числе конструкты-декларации, в ряде отраслей российского права традиционно внедрены в его ткань и юридически значимы, являясь в том числе предпосылкой для фрормулирования аналогичных предписаний в конкретных институтах. Например, в цивилистике (и гражданско-правовой, и семейно-правовой сфрерах) фрлагманом подобного рода выступает конструкция добросовестности, добрых нравов. В пространстве же семейного права таких конструктов неизмеримо больше - «достойное поведение», «взаимоуважение», «нравственное развитие» и др. [6, с. 53-65; 17, с. 57-58]. Следовательно, опасливое отношение к декларативным юридическим формулировкам не имеет под собой безусловного основания [18].

Из иных декларативных образцов наиболее актуальным является конструкция из области медицинского законодательства - обязанности гражданина заботиться о сохранении своего здоровья. Данная обязанность предусмотрена нормой ч. 1 ст. 27 ФЗ «Об основах охраны здоровья граждан в Российской Федерации». Она фрагментарно конкретизирована в правилах ч. 2 (об обязательных медосмотрах в предусмотренных законом случаях; обязанности медобследования в связи с опасными заболеваниями, соответствующего лечения и профилактики) и ч. 3 (об обязанности соблюдать режим лечения в период временной нетрудоспособности). 
Данная обязанность конкретизируется также многочисленными ведомственными нормативно-правовыми актами. Однако за пределами данной конкретизации обязанность остается не просто декларативной, а спорной с точки зрения ее права на существование. Главным контрагрегатором в данном вопросе выступает конструкция права распоряжаться своей жизнью, которая, в свою очередь, является частью содержания права на жизнь. Последнее включает в себя «право родиться» (также не бесспорное или, по крайней мере, не абсолютное, так как ему противостоит право женщины принимать решение о вынашивании плода), право рисковать своей жизнью (в результате выбора профессии с опасными условиями труда, занятий опасными видами спорта или незапрещенными видами развлечений, участия в испытаниях и исследованиях технических средств, вакцины и пр.), в каком-то условном смысле - «право на самоубийство» и право на эвтаназию по законодательству некоторых стран (непременно - Нидердандов и Бельгии) [19]. Соответственно праву на жизнь корреспондирует обязанность государства и других граждан воздерживаться от нанесения ущерба здоровью и от покушения на жизнь конкретного человека.

Очевидно, что если хотя бы в определенной мере гражданин обладает законной возможностью рисковать своей жизнью, то у него неизбежно возникают правомочия, кроме специальных случаев (ст. 27 означенного ФЗ), не проявлять заботы о своем здоровье (в понимании указанного Ф3), а следовательно, и не быть субъектом рассматриваемой обязанности ${ }^{7}$ В доктрине предпринимаются попытки найти тонкую грань между обязанностью и необязанностью [20]. В частности, отмечается, что выходить в толковании первой за пределы случаев, прямо предусмотренных законом, опасно, чревато недоразумениями. Так, если квалифицировать ее как всеобщее долженствование, то придется изобретать меры воздействия на граждан, не принимающих зимой и ранней весной витамины (а ведь - авитаминоз!), игнорирующих утреннюю гимнастику (сними подтверждающее видео, в противном случае - делай зарядку в перерыв от работы, под контролем ответственного сотрудника), одевающихся не по погоде (а как быть с купающимися в проруби?), поглощающих вредную пищу (заколотим двери кафе с фрастфудом), употреблюящих алкоголь сверх рекомендованной врачом персональной нормы (25 г коньяка после работы -для кардиокомфорта)... А для обеспечения механизма контроля за соблюдением такой комплексной обязанности - всех сосчитать,

${ }^{7}$ Кстати, возможно, и в этой ситуации следует размышлять о своеобразной конструкции право-обязанности. 
Тарусина Н. Н.

оцифровать и зачипировать. И создать специальное Ведомство - в духе Оруэлла или Замятина ${ }^{8}$.

Однако поупражняться в трепетной заботе о здоровье граждан можно и в пространстве обязывающих нормативов, предусмотренных ст. 27 ФЗ: предусмотреть, например, ежегодное подтверждение инвалидности для человека, лишенного ног (лишь недавно ушло в историю медицины); обязывать раз в три дня посещение больным поликлиники для продления больничного; требовать обязательного предварительного посещения терапевта (с записью на прием за месяц), чтобы проконсультироваться у другого врача; настаивать на выполнении норматива о ежегодном прохождении медицинского осмотра для продления трудового договора в период пандемии ${ }^{9} .$. И т. д. Список можно продолжать еще долго. Впрочем, это уже разговор не о наличии/отсутствии обязанности, а о бюрократической потребности обесточить ее от духовного начала.

Таким образом, конструкция обязанности предполагает несколько сущностей (классическую, декларативную, квазидекларативную) и вариантов взаимодействия в рамках пары «право-обязанность». Она также явным образом нуждается как в расширении сореры своего применения (например, распространении на детей, с дифреренциацией по возрасту), так и уточнении ее (дабы юридическая сила обязанности не обрушилась на не подозревающего о таковой опасности гражданина).

${ }^{8}$ Если декларативная обязанность детей уважать своих родителей и помогать им ассоциируется с темой «ангел пролетел...", то обязанность по сохранению своего здоровья, в ее декларативной части, чревата ассоциацией с «улыбкой сатаны».

${ }^{9} \mathrm{~B}$ том числе для 65 плюс, о которых - забота особая: постоять в очереди в регистратуру вместе с «безсимптомной» молодежью, зачем-то нанести визит, согласно записи в медкнижке, к стоматологу (с кариесом работать по профессии нельзя) и т. п.

\section{Ссылки}

1. Шершеневич Г. Ф. Учебник русского гражданского права. Казань, 1905. 795 c.

2. Иоффре О. С. Советское гражданское право. Т. 3 . М., 1965. 495 с.

3. Нечаева А. М. Обязанности по воспитанию детей в свете новой Конституции СССР // Развитие законодательства о браке и семье. М., 1978. 159 с.

4. Нечаева А. М. Семейное право. Актуальные проблемы теории и практики. М.: Юрайт, 2007. 280 с.

5. Грибанов В. П. Осуществление и защита гражданских прав. М.: Статут, 2001. $411 \mathrm{c}$.

6. Тарусина Н. Н. Семейное право: в «оркестровке» суверенности и судебного усмотрения. М.: Проспект, 2014. 288 с. 
7. Тарусина Н. Н. Семейное законодательство: «50 оттенков неопределенности» // Вестник Ярославского государственного университета им. П. Г. Демидова. Серия Гуманитарные науки. 2017. № 1. С. 50-53.

8. Леженин В. Н. Правовые вопросы семейного воспитания детей. Воронеж, 1992. $151 \mathrm{c}$.

9. Явич Л. С. Сущность права. Л., 1985. 208 с.

10. Рабец A. M. Проблемы укрепления нравственных начал в нормах о личных неимущественных правах и обязанностях родителей и детей // Научные труды РАЮН. М., 2003. № 3. С. 161-163.

11. Гражданское право / под ред. А. П. Сергеева, Ю. К. Толстого. СПб. Т. 3. $784 \mathrm{c}$.

12. Матузов Н. И. Актуальные проблемы теории права. Саратов, 2004. 512 с.

13. Тарусина Н. Н. Семейное право: очерки из классики и модерна. Ярославль, 2009, 616 c.

14. Тарусина Н. Н., Сочнева О. И. Права детей. М.: Проспект, 2019. 176 с.

15. Матвеева Н. А. Институт обязанностей ребенка в законодательстве зарубежных стран // Семейное и жилищное право. 2020. № 6. С. 25-28.

16. Тарусина Н. Н. Конституционное правосудие: о некоторых поправках в законодательство // Вестник Ярославского государственного университета им. П. Г. Демидова. Серия Гуманитарные науки. 2021. Т. 15, № 1. С. 64-75.

17. Тарусина Н. Н., Сочнева О. И. Начала правового регулирования семейных отношений: проектные предположения // Вестник Ярославского государственного университета им. П. Г. Демидова. Серия Гуманитарные науки. 2020. № 3. С. 56-61.

18. Тарусина Н. Н. Доказывание по гражданским делам из личных семейных правоотношений: трудности жанра // Вестник гражданского процесса. 2019. Т. 9, № 1. C. 254-273.

19. Тарусина Н. Н. Право распоряжаться своей жизнью: актуализация социально-политического контекста в условиях пандемии COVID-19 // Социальные и гуманитарные знания. 2021. Том 7, № 2. С. 166-181.

20. Шишков С. Н., Полубинская С. В. Забота о сохранении своего здоровья как юридическая обязанность // Государство и право. 2020. № 10. С. 81-89. 